\title{
Uses of the Outcomes of Research in Business Management and Profitability
}

\author{
Muyumbwa Kamenda', Abubaker Qutieshat ${ }^{1,2}$ \\ ${ }^{1}$ Graduate School of Business, University of Zambia, Lusaka, Zambia \\ ${ }^{2}$ Associate Member of Staff \& Honorary Researcher, The University of Dundee, Scotland, UK \\ Email: Kamendamuyumbwa6@gmail.com, abubaker@astrialearning.org
}

How to cite this paper: Kamenda, M., \& Qutieshat, A. (2021). Uses of the Outcomes of Research in Business Management and Profitability. Open Journal of Business and Management, 9, 2938-2949.

https://doi.org/10.4236/ojbm.2021.96164

Received: October 5, 2021

Accepted: November 20, 2021

Published: November 23, 2021

Copyright $\odot 2021$ by author(s) and Scientific Research Publishing Inc. This work is licensed under the Creative Commons Attribution International License (CC BY 4.0).

http://creativecommons.org/licenses/by/4.0/ (c) (i) Open Access

\begin{abstract}
This study has focused on conducting a brief literature review analyzing the impact of research outcomes on Business Management and Profitability in Organizations, focusing on how organizations have used research outcomes in Decision Making, Planning, Resource Allocation, Marketing and New Products Development (NPD). The study has articulated what different scholars have argued on how outcomes of the research have contributed to the management of organizations and thus remaining profitable. The methodology and approach of the study have been through the analysis of published literature, both empirical and theoretical literature of scholarly published journals, articles, and books, and how they have impacted business and management activities in organizations. Furthermore, the study has outlined the social and practical implications of why organizations need to use research outcomes, especially in changing business climates, in addressing and mitigating threats and aiding new product development that meets the current market trends. In addition, the study has brought out the impact of the outcomes of research in influencing policy directives that are anchored on empirical and theoretical literature in mitigating risks and avoiding organizations going out of business due to poor decision making. Finally, the study has highlighted the need for organizations to be well informed through the outcomes of research on new products to bring on the market that would be of taste to consumers and remain profitable.
\end{abstract}

\section{Keywords}

Business Management, Brief Literature Review, New Product Development (NPD), Research and Research Publications

\section{Introduction}

This study examines the body of related literature that has been done previously 
on the impact of research outcomes on business management and profitability. Research outcomes have long been recognized as the driving force of progress and innovation. In today's world, many firms have developed a competitive visionary landscape that promotes investments through innovative activities that have led to efficient and well-managed firms. Timely and appropriate investment knowledge and innovation are key to providing firms with a competitive advantage. The impact of outcomes of research on business management and profitability has been subjected to several studies. Hence, this study analyses what different scholars have argued as the impact of research outcomes on organisations remaining profitable. The study articulates the need for organisations to use outcomes of research as the basis for their organisational activities in decisionmaking processes based on empirical evidence.

The world is evolving and requires evidence-based decisions to address the emerging global challenges faced by organisations today, and hence the purpose of this study is to fill in the gaps of previous studies in ensuring that organisations can make appropriate and less risky decisions in changing business environments. The methodology and approach of the study used have been through the analysis of secondary data sources such as published literature, both empirical and theoretical literature of scholarly published journals, articles, and books, and that have impacted business and management activities in organizations. In addition, the information has been researched through a review of scholarly published articles on various platforms such as online platforms, journals and published books on business management and profitability.

Therefore, this paper is mainly structured into three parts beginning with the Introduction and overview of the study, followed by a Brief Literature Review, and then Discussions and Conclusions of the study.

\section{Overview}

Business Management refers to managing and coordinating organizational business activities, usually producing materials, money, machines, innovation, and marketing, and through management, organizations have the responsibility and power to operate, run their enterprises and make necessary decisions to ensure that the organization remains profitable (Upcounsel, 2021). Therefore, organizations are responsible for making sound decisions to ensure that they meet the organization's objectives. This requires appropriate guidance; hence the purpose of this research in analyzing how organizations could be impacted in their activities in business management and profitability. The study outlined the impact of research outcomes when organizations use them in their businesses and management activities, focusing on decision-making, marketing, and new product development. Therefore, adequate planning requires accurate information derived from research.

Research has various approaches that would include the collection, analyzing of information collected that would serve as basis for decision making. There- 
fore, scientific methods are used to test and analyze notions and hypotheses. Therefore, this paper will focus on conducting the Brief Literature Review in analyzing the impact outcomes of research on business management and profitability of organizations.

In a developing business environment, total reliance on research to make decisions is somewhat risky because research results are inaccurate. However, be cautious about how research outcomes in finding appropriate solutions, especially in problem-solving research, should not be undermined as it's an ingredient to good management in firms. And with many research findings been released, it has come out clear on the need to use outcomes of research in business activities to be efficient and meet the Market expectations. The extent to which business managers apply research findings or results in decision making in their organizations and its effect on profitability is the overall objective that this study seeks to address.

The impact of research on business management and profitability could occur both inside and outside the institution. The result within the institution refers to the contents of the research findings incorporated and applied in the execution of internal processes. On the other hand, the impact of research outcomes outside the institution refers to the content of studies appropriated and used by companies, government agencies and other external organizations.

The main problem to be addressed in studies related to the assessment of research outcome impact is the definition of what proportion of change could be attributed to research effects. In addition, the complexity of how knowledge is produced and disseminated in society makes it difficult to identify the origin and complete understanding of the causal mechanisms of the phenomenon (Albornoz et al., 2005). This complexity could be observed in various areas of knowledge. Still, it is even more evident that research impacts are not easily verifiable compared to other disciplines.

Research outcomes impact analysis could adequately be understood by considering various indicators that cause and influence these impacts. Indicators may be classified based on the dimensions on which the research creates an effect. However, it should be noted that such measurements are not independent. In this regard, the choice of methodology, indicators and data sources is crucial. Hence, they need to understand what conditions the evaluation systems encourage in fostering certain behaviours and promote an alignment of priorities to match the hands (European Commission, 2010). Such indicators may reflect the value judgments and priorities of the promoter of the evaluation. And thus, the reason why an evaluation system consensus has not yet been reached among the different evaluation systems that exist worldwide (Palomares-Montero et al., 2008).

One of the dimensions to research outcome impact is on public policy. The research outcome impact on public policy refers to the possibility of a study influencing the political agenda of many governments and would be vital in pro- 
viding information to control the processes of decision-making in the political arena or supporting the development of public policies and guidelines.

Another dimension advanced by Santos (2003) is that of innovation. The impact of research outcomes on innovation refers to studies that result in the commercialization of new products and procedures. For example, in the administration field, innovation could be related to new business models, new solutions and new managerial processes, resulting in improved profitability and business performance. Therefore, innovation brings about Product Development, which has various stages, from the initial points or concepts to the stages where consumers have access to it and beyond (Product Plan, 2021). New Product Development Research and Development focus on multiple steps in the NPD process, such as obtaining ideas for new products through primary research that focuses on the current conditions in the market and consumer tastes in the company's $R \& D$ entities, business practitioners, workers, salespeople, corporate spies and many more. All these activities have culminated into products being launched in the market by targeting the appropriate market audiences (UK Essays, 2018).

This shows that NPD requires information in ensuring that the appropriate products are designed to meet the expectations of the markets and the consumers. Hence, this research aims to ascertain how the research outcomes could impact the organization's business management and profitability activities.

\section{Empirical Literature}

Innovativeness, a product of research, is considered an essential element in organization growth strategies and guides organizations to explore available market opportunities and increase market share to enjoy their profits. This is because innovation is key in stirring profitability and leads to dynamic business experiences that would improve the organization's performance in the markets and maintains a favourable status in customers' opinion, primarily through the establishment of new products on the needs that meet the current tastes and preferences of the consumers.

In trying to understanding evolution and the impact of innovation, Roger (2003) developed the diffusion theory of innovation. The theory articulates how innovation could spread out in its initial processes through specific channels and how it could be communicated amongst members of a system over time. The theory indicates that four elements are involved in the process of generating ideas, implementation and dissemination. The idea should first be synthesized and classified as an innovation (Mayer \& Argyres, 2004).

Wilkinson and Thomas (2014) suggest that firms that do not engage in research and development face underperformance or dissolution. The authors underscored the need for firms to undertake research as it enables them to create new products that would help them be competitive.

Mugalisi (2015) undertook a study to establish the effect of Research and De- 
velopment on the performance of many companies listed at the Nairobi Securities Exchange. And that the descriptive research, together with the secondary data used, were from published financial statements of the years 2010 to 2014 . The study focused on 17 companies that are listed at the Nairobi Securities Exchange. Statistical methods such as regression analysis, focusing on descriptive statistics, were used in the study to analyze data. The study outcomes were that firms, especially those that use and rely on technology to identify opportunities, could exploit innovative activities such as creating new products and services to be profitable. This meant that considerations for firms to invest in research and Development (R\&D) should be amongst the firm's priorities. The study's outcomes initially showed that $R \& D$ in the short run would significantly put a strain on financial performances. In contrast, in the long run, the firms observed that investment returns were gained from the strategies recommended from the $R \& D$, which improved the firms' outcome in terms of financial performances.

Wasike (2014) conducted a case study of Haco tiger brands in east Africa on research and development expenditure on firms' performance. The data analysis using a longitudinal study design indicated that secondary data collected from the report showed an annual financial sales report from 2009 to 2014, which significantly contributed to product innovation. This subsequently contributed to the sales growth of the company and helped to accelerate total company sales revenue. Research and development thus influenced the performance of Haco Tiger Brands positively.

Van de Vrande et al. (2009) undertook a research study to investigate the effect of business research and innovation on SME's. The study was conducted in the Netherlands for over seven years. Therefore, Secondary data obtained from about 605 such firms were analyzed through a census study. The study indicated that elements in business research and innovation were practised over a given period. Furthermore, the study highlighted that no significant differences between services and manufacturing industries. In addition, the study found that medium-sized firms engage more in business research and innovation than smaller firms.

Corsino (2008) also undertook a research study to investigate the effect of research and development innovations on firm growth in London. Descriptive research design and secondary data were obtained from various organizations covering seven years. From the captioned population of 524 firms, a sample of 45 firms was selected. Data were analyzed using regression analysis. The research study concluded that incremental innovation increases the performance involved in the production process and, after that, the firm's ability to remain in the market.

Calantone et al. (2002) argues that the capability of firms in product and business innovation is key for them to exploit new opportunities in seeking to gain a competitive advantage in markets. He notes that research is a fundamental element of innovative performances which improves productivity and ultimately 
enhances financial performance and profitability.

Anagnostopoulou and Levis's (2008) studies on research and development examined the sustainability of business growth and market performance due to R\&D investments. The study, with an extensive data set from the UK, was researched from 1990-2003. The findings provided evidence supporting the steady growth relationship with gross income and R\&D intensity and sales. However, while study findings exhibit a positive relationship between R\&D intensity and profits, it displays that $R \& D$ intensity improves continuity in share returns.

Artz et al. (2010) carried out an analysis using 272 US firm data from 1986 to 2004 sought to understand the relationship between R\&D expenditures, inventions and innovation in terms of products and their impact on financial performance. Study findings have found that new product announcements are positively associated with financial performance.

Bradbury (2015) undertook a study to evaluate the application of research in business and management. The study established that research in strategies and practical tasks in structured hierarchical organizations was vital in balancing theory and practice. They further acknowledged that research contributes to creating areas of possible collaboration that are more inclined to learning, designing, enactment and evaluation of liberating actions through processes such as combining action and reflection in co-generative knowledge. Research focuses on bringing about change in organizations, developing self-help competencies in organizational members and contributing to the broad array of scientific knowledge.

Barabba (1994) asserts that managers can create dynamic, market-based decision-making mechanisms to competitive advantage. He further indicated that new strategic approaches to marketing have helped firms attain a principle of market leadership that focuses on transforming information obtained through research into shared knowledge. Furthermore, the quality of learning would aid appropriate and correct actions by organizations.

Lewis (1990), in discussing the concept of the "intelligence corporation", notes the critical importance of research in the successful execution of corporate strategies. He argues that companies must fully understand various players' signals in such markets to launch their products and services on the market profitably. Accordingly, firms that lose touch with the market, either by ignoring or misinterpreting its signals, will fail to take advantage of the opportunities in the competitive environment. Churchill (1991) suggests that market research is a significant source of information that affects marketing decision-making as it serves as the firm's formal communication link with the environment.

Anthony (1994) suggests that firms should build up a comprehensive and dynamic knowledge base about their markets and about those who consume their products. With such specific knowledge, effective targeting strategies can be developed to ensure sustained business growth and profitability. He further posits that the discipline of fact- based analysis is fundamentally relevant in optimizing 
profits in customer-oriented entities and aid efficient delivery of goods and services. Furthermore, that business activities needed more analytical and systematic approaches. Thus, market research has led to assessing customer requirements in maximizing net profits by providing customers with appropriate products and services according to their tastes.

Hamlin (2000) claims that market research is used as part of a decision-making process, usually deploying company assets to achieve a specific result. Concerning the decision-maker, the ultimate consumer of such research. He notes that his claim allows him to make the pragmatic definition of the scope of the research. Effective research supports the rational selection of a course of action that will lead to an outcome that is satisfactory to the decision-maker

Deshpande and Jeffiies (1981) studied marketing managers' utilization of market research information in decision making. Their study established that the manager's use of market research was influenced by various factors, including conformity to expectations, clarity of presentation, research quality, and political acceptability. Subsequently, Deshpande and Zaltman (1982) assessed the linkages of these factors to research utilization and reported that the elements were significantly related. They noted that managers tended to accept information that was deemed technically adequate, confirmed prior expectations and those in which managers worked closely with the researchers. In an extension of this work, Deshpande and Zaltman (1984) compared the perceived influence of the managers and researchers. They established that, in general, market researchers did not share managers' views on the importance of political acceptability and conformity to prior expectations.

Moorman, Zaltman and Deshpande (1992) further claim that trust in research providers is essential to research outcomes utilization. This is from an understanding that trust reduces perceived uncertainty and vulnerability associated with using research information. They stated that uncertainty may come in for several reasons and that managers, firstly, would often feel to have more available information than it is necessary for the decision-making process; And that secondly, increasing research techniques and advanced technologies would make it difficult for some managers to be able to use research processes; Furthermore, Thirdly, problems involving volumes and sophistication could be exacerbated by a growing number of customers who are unfamiliar with research processes and how to use it in decision-making.

Additionally, most firms endeavour to minimize operating expenses by relying on support from external research organizations other than from their internal staff. However, this has consequences such as creating short term relationships with researchers who have no working experience with the firms and may not have all the details in having access to all the information. Mintzberg (1975) investigated the factors the hinder managers from effectively using research findings. His findings showed that managers do not often utilize research information as they should because of problems in the functioning of organiza- 
tions. He claims that power and politics within the organizations could lead to managers ignoring or distorting information that would affect overall effectiveness. Political tactics such as withholding or distorting information and even overwhelming or submerging others with information are frequently used (Allen et al., 1979).

Piercy (1980) proposes that research information is an essential tool in the organizational power struggle as it creates a basis for decision making processes and possible alternatives. Davis and Olson (1985) also suggest that rather than acting with complete rationality, there is evidence that people often depend on experience, inductive inference and intuition in making decisions.

John and Martin (1984) study established that research cultures that promote change and innovative behaviour would encourage the active exchange of ideas and increase communication flows. Such research-oriented cultures would be very appropriate, emitting a general atmosphere of being inventive, willing, and creative in taking chances. Managers operating in such an atmosphere of that culture need to promote exchanging information and boundary-spanning behaviour actively. Still, they would bring about the adoption and use of new ideas and concepts.

The views and concepts may have originated outside their immediate workgroup. For example, Deshpande and Webster Jr. (1989) argue that organizations which welcome change often propagated by research are more likely to compete favourably on markets and enhance their profitability and market share.

Therefore, business information helps organizations to make informed decisions to mitigate risks and threats in their organizational activities. Johnson (1984) argued that there was a need for professionalism in organizations as it was a key and an essential ideology that would aid effective operations of organizations to base their activities on superior knowledge claims, which was a key ingredient to the process of decision making. Therefore, decision making requires superior knowledge to ensure that the respective organizations make the right and appropriate decisions in acting professionally.

Furthermore, Puranam and Vanneste (2016) mentioned that the process of making high-level strategic decisions could be a daunting challenge in most business and management activities, especially that it involved managing interactions between different businesses with diverse portfolios, which made it critical for organizations to focus on decisions which were made based on insufficient information. Therefore, the authors argued and stressed the need to make decisions based on sufficient information to aid effective business operations and management activities.

\section{Discussion}

This brief literature review on the impact of research outcomes on business and management in organizations has demonstrated how organizations need to use these outcomes for their business management and profitability processes in de- 
cision making, marketing, designing and producing new products for consumers in meeting their market expectations. In addition, one of the critical influences of the outcomes of research is its impact on public policy. This usually is attributed to influence the political agenda and decisions of governments and Organizations. Therefore, this review undertook to understand how different scholars highlighted the benefits of using the outcomes of research in the organizations to ensure that organizations could remain profitable by meeting the expectations of the appropriate audiences and their respective tastes and preferences.

Therefore, this research has found out that for organizations to ensure effective management operations and remain profitable, there is a need to include innovation strategies in the company operations, in marketing and base the decision-making process on research outcomes. In addition, from the review, it is clear that scholars organizations needed to use research outcomes to design new products that would meet the consumers' tastes and preferences. Therefore, the results of the research have proved to be a vital ingredient to successful organizational operation.

Therefore, organizations need to plan and include innovation, marketing and research-based decision-making strategies to minimize risks and run into losses in their operations. And innovative strategies would help organizations be up to date with the new and current prevailing trends of goods and services that would be of interest to consumers. This is achieved through research and development to ensure that research findings guide business decisions. Unfortunately, this further eludes to tailoring services and products that target clusters of consumers to optimize value.

\section{Conclusion}

Finally, the review has highlighted the importance of outcomes of research in harnessing operations of organizations in their business and management activities to ensure that they remain successful and the need for researchers, managers of organizations to collaborate on key and priority areas that require the attention of researchers in predicting the Business environments. The impact of research outcomes on Business Management and Profitability could be inaccurate when not correctly interpreted. However, the purpose of this research is to guide business decisions, lower-cost drivers, problem-solving, proportion changes in resource allocation to maximize revenue. Thus, providing the most needed rationale for future research on how organizations could use the outcomes of research to frame and guide their activities to provide the most needed guidance to policymakers in governments and other decision-making bodies and organizations. In this way, research outcomes can inform public policy and research development to remain profitable.

\section{Acknowledgements}

I would like to acknowledge the support rendered to me by my colleagues, friends 
and Family in conducting the Literature review on the uses of outcomes of Research in Business Management and Profitability.

\section{Conflicts of Interest}

The authors declare no conflicts of interest regarding the publication of this paper.

\section{References}

Albornoz, M., Estebanez, M. E., \& Alfaraz, C. (2005). Scope and Limitations of the Notion of Social Impact of Science and Technology. Ibero-American Journal of Science, Technology and Society-CTS, 2, 73-95.

Allen, R. W., Madison, D. L., Porter, L. W., Renwick, P. A., \& Mayes, B. T. (1979). Organizational Politics: Tactics and Characteristics of Its Actors. California Management Review, 22, 77-83. https://doi.org/10.2307/41164852

Anagnostopoulou, S. C., \& Levis, M. (2008). R\&D and Performance Persistence: Evidence from the United Kingdom. The International Journal of Accounting, 43, 293-320. https://doi.org/10.1016/j.intacc.2008.06.004

Anthony, F. (1994). Marketing Is in Crisis-Can Marketing Research Help? Journal of Marketing Research Society, 36, 23-26.

Artz, K. W., Norman, P. M., Hatfield, D. E., \& Cardinal, L. B. (2010). A Longitudinal Study of the Impact of R\&D, Patents, and Product Innovation on Firm Performance. Journal of Product Innovation Management, 27, 725-740. https://doi.org/10.1111/j.1540-5885.2010.00747.x

Barabba, P. (1994). Market-Based Decisions. Dartnell Corporation

Bradbury, H. (2015). The SAGE Handbook of Action Research. Sage. https://doi.org/10.4135/9781473921290

Calantone, R. J., Cavusgil, S. T., \& Zhao, Y. (2002). Learning Orientation, Firm Innovation Capability, and Firm Performance. Industrial Marketing Management, 31, 515-524. https://doi.org/10.1016/S0019-8501(01)00203-6

Churchill. G. A. (1991). Marketing Research: Methodological Foundations. Dryden Press.

Corsino, M. (2008). Product Innovation and Firm Growth: Evidence from the Integrated Circuits Industry.

Davis, G. B., \& Olson, M. H. (1985). Management Information System: Conceptual Foundations, Structure, and Development (pp. 532-533). McGraw-Hill Book Co.

Deshpande, R., \& Jeffries, S. (1981). Attitude Affecting the Use of Marketing Research in Decision Making: An Empirical Investigation. In K. L. Bernhardt, et al. (Ed.), Educators' Conference Proceedings (pp. 1-4). American Marketing Association.

Deshpande, R., \& Webster Jr., F. E. (1989). Organizational Culture and Marketing: Defining the Research Agenda. The Journal of Marketing, 53, 3-15.

https://doi.org/10.1177/002224298905300102

Deshpande, R., \& Zaltman, G. (1982). Factors Affecting the Use of Market Research Information: A Path Analysis. Journal of Marketing Research, 19, 14-31. https://doi.org/10.1177/002224378201900102

Deshpande, R., \& Zaltman, G. (1984). A Comparison of Factors Affecting Researcher and Manager Perceptions of Market Research Use. Journal of Marketing Research, 21, 3238. https://doi.org/10.1177/002224378402100104 
European Commission (2010). Assessing Europe's University-Based Research: Expert Group on Assessment of University-Based Research. Publications Office of the European Union, Luxembourg.

http://ec.europa.eu/research/era/docs/en/areas-of-actions-universities-assessing-europ e-university-based-research-2010-en.pdf

Hamlin, R. (2000). Designing Market Research to Support Marketing Action or How to Ask the Right Questions, Rather than How to Ask the Questions Right. In Proceedings of the Pan-Pacific Conference (pp. 349-352). Queenstown.

John, G., \& Martin, J. (1984). Effects of Organizational Structure of Marketing Planning on Credibility and Utilization of Plant Output. Journal of Marketing Research, 21, 170183. https://doi.org/10.1177/002224378402100205

Johnson, T. J. (1984). Professionalism: Occupation or Ideology. In: G. Sinclair (Ed.), Education for the Professions: Quis Custodiet? SRHE and NFER. Nelson Pub.

Lewis, B. (1990). Marketing Success in the 1990s: Characteristic of the Intelligent Corporation. Information Management Review, 5, 15-22

Mayer, K. J., \& Argyres, N. S. (2004). Learning to Contract: Evidence from the Personal Computer Industry. Organization Science, 15, 394-410.

https://doi.org/10.1287/orsc. 1040.0074

Mintzberg, H. (1975). Impediments to the Use of Management Information. National Association of Accountants.

Moorman, C., Zaltman, G., \& Deshpande, R. (1992). Relationship between Providers and Users of Market Research: The Dynamics of Trust within and between Organizations. Journal of Marketing Research, 29, 314-328.

https://doi.org/10.1177/002224379202900303

Mugalisi, P.A. (2015). Effect of Research and Development on the Firm Performance of Manufacturing Companies Listed at the Nairobi Securities Exchange. An Unpublished MBA Project, University of Nairobi.

Palomares-Montero, D., García-Aracil, A., \& Castro-Martínez, E. (2008). Evaluation of Higher Education Institutions: Bibliographic Review of the System of Indicators. Spanish Journal of Scientific Documentation, 31, 205-229. https://doi.org/10.3989/redc.2008.v31.i2.425

Piercy, N. (1980). Marketing Information Systems: Theory vs Practice. Quarterly Review of Marketing, 6, 16-24

Product Plan (2021). What Is Product Development? https://www.productplan.com/learn/what-is-product-development/

Puranam, P., \& Vanneste, B. (2016). Corporate Strategy Decision Making. Cambridge University Press. https://doi.org/10.1017/CBO9781316343234

Rogers, E. M. (2003). Diffusion of Innovations (5th ed.). Free Press.

Santos, R. (2003). Scientific Production: Why Measure? What to Measure? Digital Journal of Librarianship and Information Science, Campinas, 1, 22-38.

UK Essays (2018, November). Impacts and Importance of New Product Development Marketing Essay.

https://www.ukessays.com/essays/marketing/impacts-and-importance-of-new-product -development-marketing-essay.php?vref=1

Upcounsel (2021). Business Management Definition: Everything You Need to Know. https://www.upcounsel.com/business-management-definition

Van de Vrande, V., De Jong, J. P., Vanhaverbeke, W., \& De Rochemont, M. (2009). Open 
Innovation in SMEs: Trends, Motives and Management Challenges. Technovation, 29, 423-437. https://doi.org/10.1016/j.technovation.2008.10.001

Wasike, N. S. (2014). Product Innovation and Performance of Haco Tiger Brands East Africa. An Unpublished MSc Project, University of Nairobi.

Wilkinson, T. J., \& Thomas, A. R. (2014). Innovation's Second Step. Thunderbird International Business Review, 56, 273-284. 